\title{
América se hurga el ombligo
}

\section{América revisa seu umbigo}

\section{America delves into its navel}

\author{
Luis E. Arévaloi
}

Palabras clave:

Identidad cultural

Latinoamérica

Pueblos Indígenas

Modernismo

Lo Real Maravilloso

\section{Resumen:}

Este trabajo examina el diálogo a distancia que sostienen los autores modernistas y real-maravillosos para formular un algoritmo que racionalice la respuesta americana frente a la dilución, asimilación y coacción de las identidades locales con que nos regala la globalización. El ensayo se compone de tres secciones. La primera contiene una descripción de los aportes modernistas a la construcción de una identidad continental y sus contradicciones; la segunda, los esfuerzos de los autores real-maravillosos por refinar un nuevo perfil del latinoamericano a partir de la propuesta modernista; finalmente, la tercera sección propone ejemplos de aplicación del principio rector ofrecido por los autores real-maravillosos. 


\begin{abstract}
Resumo:
Este ensaio apresenta um diálogo, sustentado a distância, entre os autores modernistas e "real-maravillosos" da primeira metade do século XX. Depois de reconstruir esses intercâmbios, o artigo revela um algoritmo com o qual os latino-americanos têm enfrentado a diluição, assimilação e cooptação de identidades regionais provocada pelo processo de globalização. $O$ artigo contém três secções. A primeira descreve as contribuições dos autores modernistas para a construção de uma identidade latino-americana pós-colonial e suas contradições. A segunda destaca os refinamentos que autores "real-maravillosos" têm operado sobre o perfil cultural da América Latina oferecido por contribuições dos modernistas. Finalmente, a terceira parte apresenta três exemplos de aplicação do princípio geral proposto pelos autores real maravilhosos.
\end{abstract}

\section{Palavras chave:}

A identidade cultural

América Latina

Povos Indígenas

Modernismo

Realismo Mágico

\section{Keywords:}

Cultural Identity

Latin America

Native Americans

Modernism

Magical Realism

\section{Abstract:}

This paper examines a dialogue, sustained at a distance, between Modernist and Real-Marvelous authors of the first half of the Twentieth Century. Upon reconstructing these exchanges, the article uncovers an algorithm with which Latin Americans have faced the dilution, assimilation, and cooptation of regional identities brought about by the process of Globalization. The article contains three sections. The first one describes Modernist authors' contributions to the building of a postcolonial Latin American identity and its contradictions. The second one highlights the refinements Real-Marvelous authors operated upon the novel Latin American cultural profile offered by Modernists' contributions. Finally, the third part presents three applications of the general principle proposed by the Real Marvelous authors. 


\section{América se hurga el ombligo}

La definición de la identidad cultural de América está aún por finalizarse. No es por desatención a la importancia del empeño, sino a su complejidad. Este ensayo franquea parcialmente esa dificultad al conectar la producción literaria de las primeras dos terceras partes del siglo $X X$ con la construcción de una identidad cultural latinoamericana moderna. Específicamente, este trabajo examina el "diálogo" diacrónico entre los autores modernistas y real-maravillosos para formular un algoritmo que racionalice la respuesta americana frente a la dilución, asimilación y coacción de las identidades locales con que nos regala la globalización.

El ensayo está dividido en tres partes. La primera contiene una descripción de los aportes modernistas a la construcción de una identidad continental y sus contradicciones; la segunda, los esfuerzos de los autores real-maravillosos por refinar un nuevo perfil del latinoamericano a partir de la propuesta modernista; finalmente, la tercera sección propone ejemplos de aplicación del principio rector ofrecido por los autores real-maravillosos.

El año 1888ii inaugura el Modernismo como una forma de hacer arte y literatura en América. Antes de este movimiento, los temas, los personajes, y aun los paisajes latinoamericanos exudaban un aroma europeo. La fuerte asociación de esa fecha con el despertar intelectual de América queda sobradamente reconciliada con la realidad. Con creces, las publicaciones de José Martí y Rubén Darío presentan una visión de América, desde América. La visión Modernista de América es un efecto directo de las reformas liberales iniciadas después de la independencia formal de España y alargadas hasta la década de 1880. Dichas reformas, entre otras cosas, facilitaran la creación un mercado interno y favorecieron el acceso a la educación de la clase media. El efecto neto fue el surgimiento de un público lector, en posición de articular un proyecto de nación con que América participarían en el mercando mundial de principios del siglo XX.

Martí y Darío coincidieron en articular una visión de América que recogía retazos de un mundo que el aislamiento colonial nos había vedado. A pesar de lo innovadora que parecía la visión modernista era tan solo la culminación del proyecto de la ilustración. Martí intuía esa disonancia. En el ensayo "Nuestra América", Martí exploró la posibilidad de una producción cultural cuyo dinamismo transformador residiera en lo americano, pero también lamentaba que "[L]a colonia continu[ara] viviendo en la república" (MARTÍ, 2013, p. 224). Martí describía América de finales de Siglo 19 como un collage en busca de un principio organizador. En sus palabras: "[...] Éramos una visión, con el pecho de atleta, las manos de petimetre y la frente de niño." En fin, continuaba Martí, "Éramos una máscara, con los calzones de Inglaterra, el chaleco parisiense, el chaquetón de Norteamérica y la montera de España." La colonia, refugiada en la ciudad, excluyó con miopía soberbia, al campesino, al indio y al negro en la construcción de una nueva identidad cultural poscolonial. Mas acordó sin reparos hacer descansar la reconstrucción de las economías nacionales en los hombros de los excluidos. Perdimos la oportunidad de articular la americanidad sobre una base amplia y la verdadera creatividad hubiese consistido, según Martí (2013, p. 224), "en desestancar al indio; en ir haciendo lado al negro [...]; en ajustar la libertad al cuerpo de los se alzaron y vencieron por ella.". Imagino que para los "criollos exóticos" que heredaron la administración colonial, la inclusión de lo vernáculo significaba un retroceso, aspecto que fue ampliamente reiterado en obras tales como Civilización y barbarie, Huasipungo, La charca. Martí percibía la vacilación de los criollos y no se 
complicaba porque las identidades americanas acusaran un decido sabor local. Comparando la construcción de la identidad latinoamericana a la producción de vino Martí reivindicaba lo popular: "El vino, de plátano; y si sale agrio, es nuestro vino" (Idem).

Darío, en "Palabras liminares" reconocía que la primera obligación del latinoamericano pensante era crear (DARIO, 2006, p. 5), y pensar sin imitar. Mas su producción abundaba en gráfico exotismo de ninfas, sátiros y centauros griegos; príncipes árabes e hindús, pedrería y flores del mundo entero. Coincidiendo con Martí, Darío aceptaba que la forma seguía siendo importada. Aún más, Darío reconocía tácitamente que, como ciudadano y poeta, para tramar su literatura lo tendría que hacer en la lengua heredada de la colonia, la cual tendría que ser modulada para entonarla a las circunstancias de una América híbrida y multicultural. A ese respecto afirmaba:

\begin{abstract}
¿Hay en mi sangre alguna gota de sangre de África, o de indio chorotega o nograndano? Pudiera ser, a despecho de mis manos de marqués: mas he aquí que veréis en mis versos princesas, reyes, cosas imperiales, visiones de países lejanos o imposibles: ¡qué queréis! yo detesto la vida y el tiempo en que me tocó nacer; y a un presidente de República no podré saludarle en el idioma en que te cantaría a ti, joh Halagabal! de cuya corte - oro, seda, mármol - me acuerdo en sueños... (DARIO, 2006, p. 5)
\end{abstract}

En un esfuerzo - sospecho - por escapar la banalidad del lenguaje, Darío proponía que la autenticidad consistía en moldear una visión americana, nuestra y en nosotros; en perseguir una "estética acrática" que permitiera al americano reivindicar que la voz poética - la que transforma la realidad - residía "en las cosas viejas, en Palenke, y Utatlán, en el indio legendario, y en el inca sensual y fino." (Idem) A pesar de sus "manos de marqués", Darío--coinci- diendo con Martí--asentía que la potencia del perfil cultural del americano tenía que ser medida por la inclusión de lo indígena.

En 1928, Pedro Henrique Ureña escribe Seis ensayos en busca de autor en los cuales decanta el pensamiento de Martí y Darío. Ureña sostiene que las contribuciones europeas a la construcción de lo americano es la botella, la forma, en que se atrapa al genio americano; mas el contenido, afirmaba Ureña, "el carácter original de los pueblos viene de su fondo espiritual, de su energía nativa" (UREÑA, 2013, p. 308).

En los treinta y seis años en que, de manera ya robusta o exánime, existió el Modernismo no dejó de reconocerse como un movimiento concentrado en la forma. $Y$ no podía aspirar a más, ya que los hábitos coloniales aún pesaban en el ritmo de la vida de las incipientes repúblicas. Si hubo un cambio fue para cimentar la lengua del colonizador, el liberalismo económico inglés y la democracia a la francesa y estadounidense. A pesar de los cientos de lenguas que sobrevivieron el periodo colonial, y la existencia del Náhuatl, el Quechua, el Aimara y el Guaraní, cuatro troncos lingüísticos viables, la lengua que ganó en difusión fue el español. En suma, el Modernismo, aunque refunfuñara a veces contra Roosevelt y el materialismoiii, celebró el progreso económico liberal y cantó a la libertad parlamentaria en español.

Martí, Darío y Ureña se percataron de la dificultad de ser americano en el envase impuesto por y desde la colonia. Aunque su respuesta, alucinadoramente realista, consistiera en sugerir la independencia de las ideas, en animar la creación de respuestas vernáculas a la situación del indígena y el negro americano, los modernistas no pudieron escapar de la camisa de fuerza de la sociedad republicana. El algoritmo estaba definido: ser americano consistía enser parte del mercado de trabajo y consumo, votar y educarse en español. 
A principios del siglo $X X$, el liberalismo económico, la democracia parlamentaria y la educación eran experiencias urbanas, de las cuales las comunidades indígenas fueron metódicamente excusadas. En otras palabras, la modernidad les negó a los pueblos originarios la ejecución del perfil cultural que potencialmente les habría incorporado a la sociedad republicana. En la práctica, la sociedad de principios de siglo XX se definía a sí misma, con lapidaria exactitud, por la exclusión de su parte indígena.

Con ciertas discontinuidades, la visión Modernista sirvió de antítesis al perfil cultural ofrecido por los autores de lo realmaravilloso. En 1949, Alejo Carpentier publicó El reino de este mundo. En el prólogo de esta novela, Carpentier renovaba las claves para interpretar la realidad americana. Específicamente anunciaba que la objetividad del positivismo europeo no alcanzaba a abarcar la riqueza de la realidad americana que ya había logrado poblar las crónicas coloniales de sirenas, amazonas, dorados y fuentes de la juventud. La contribución de Carpentier consistió en una lúcida revelación de América en donde lo real y lo maravilloso no se remilgan en hermanarse. Lo maravilloso de América, según Carpentier, tenía su génesis en "una inesperada alteración de la realidad... una revelación privilegiada de la realidad,... una iluminación inhabitual...favorecedora de las inadvertidas riquezas de la realidad" (CARPENTIER, 1967, p. 6). En Carpentier, la forma y el contenido de la literatura modernista equivalían a lo real y lo maravilloso, respectivamente. La realidad no podía existir en exclusión de lo maravilloso. Así, en el espacio discursivo donde los modernistas aceptaron la práctica del español, el consumismo y el voto como rasgos distintivos de la identidad americana; Carpentier instalaba una revelación en la cual las escalas, la perspectiva, la intensidad y la fe con que se abordaba la realidad producían una percepción gustosa e inadvertida de la realidad americana. Con esto Carpentier concedía a la cosmovisión indígena - y a todos los discursos marginados por el racionalismo - un turno en el podio desde el cual imaginarse América.

Los perspectiva modernista de América había confiado en, transado con o aceptado, algunas veces a regañadientes, el proyecto de la ilustración europea. En dicha visión, América evolucionaba hacia un futuro inexorable y moderno que le servía de único horizonte de sentido. Así construida, América era imaginable únicamente a través de los lentes del liberalismo político y económico; es decir, que del infinito número de futuros posibles, la ilustración solo nos ofrecía uno. Los autores real-maravillosos turbaron esa reducción. Propusieron que aceptar la infinidad de futuros posibles era un acto de fe en la existencia de las otras Américas posibles. Aseveraban que el Macondo de García Márquez, el Sur mítico de Borges, la Zona Rosa de Manlio Argueta, eran retazos de un futuro refugiados en el discurso popular americano. Creer en un futuro diferente del dibujado por la ilustración anunciaba "una inesperada alteración de la realidad...una iluminación inhabitual...favorecedora de las inadvertidas riquezas de [esa] realidad" tal como Carpentier (1967, p. 6) lo había propuesto en el prologo al Reino de este mundo.

Más aún, reconocía que esos futuros posibles afirmaban el proyecto de nación de los grupos que ahora imaginaban América, y una exclusión de aquellos que por falta de fe en lo maravilloso pensaban imposible un futuro indígena, mulato o mestizo. A este respecto Carpentier afirmaba "[p]ara empezar, la sensación de lo maravilloso presupone una fe. Los que no creen en santos no pueden curarse con milagros de santos, ni los que no son Quijotes pueden meterse, en cuerpo, alma y bienes, en el mundo de Amadís de Gaula o Tirante el Blanco." (Idem)

En suma, las contribuciones de los autores de lo real-maravilloso son dos. Pri- 
mero, enriquecieron el espíritu creativo del Modernismo al incluirlos discursos antes al margen. Segundo, propusieron la fe en la existencia de futuros alternos como el elemento indispensable de la nueva identidad cultural latinoamericana. Es decir, en el nuevo algoritmo, solo aquellos que creyeran posible los proyectos de nación indoamericana, negro-americana, o mestiza podían considerarse latinoamericanos.

Medio siglo después que Carpentier propusiera este nuevo arte combinatorio, la literatura se pobló de respuestas americanas que parecen funcionar dentro del algoritmo propuesto por Carpentier. La actividad literaria de los últimos cincuenta años abunda en voces antes silenciadas. Tres ejemplos ilustran este nuevo giro. Primero, el ritmo de la guaracha y la improvisación de los programas radiales interrumpen la placidez narrativa del bolero y la novela en la Guaracha del macho Camacho. En ella, Luis Rafael Sánchez presenta al puertorriqueño lisonjeando la vida al ritmo de guaracha y ofreciendo el formato burlón de los programas mañaneros de radio como instancia organizadora de la vida de un Caribe todavía colonial. Segundo, Manlio Argueta en Un día en la vida y Cuscatlán donde bate la mar del sur escribe las novelas de la esperanza. En ellas plantea el nexo vital del campesino e indígena cuscatleco con la tierra y abre la posibilidad de imaginar un futuro en el cual éstos retornen al solar del cual las reformas liberales les aliviaron. Tercero, Roberto Bolaño detectives salvajes satiriza las contradicciones de los debutantes de poetas, agitadores políticos, ricos venidos a menos, estudiantes profesionales; inmigrantes todos, ciudadanos de la globalización.

Finalmente, el algoritmo propuesto por Carpentier presupone la fe en la multiplicidad de futuros posibles, en la existencia de una América con alternativas generadas desde los intereses de las voces suprimidas. Algunos de estos horizontes son alentadores; otros, no tanto. Mas en la construcción de los futuros posibles de América, iqué importa si el vino no sabe a vino! Lo que importa es que reconforte.

\section{Bibliografía:}

CARPENTIER, Alejo. Prologo. El reino de este mundo. Carpentier. México: Compañía General de Ediciones S.A., 1967. p. 5-8.

DARÍO, Rubén. Palabras liminares. Prosas profanas, 4-5. Darío. Biblioteca Virtual Universal. Editorial el Cardo, 2006. Disponible en <http://www. biblioteca.org.ar/libros/131996.pdf>. Acessado en 5/abril/2015.

HENRÍQUEZ UREÑA, Pedro. "El descontento y la promesa" Voces de Hispanoamérica: Antología literaria. Comp. Raquel Chang-Rodríguez y Malva E. Filer. Boston: Heinle, 2013. p. 304-310.

MARTÍ, José. "Nuestra américa" Voces de Hispanoamérica: Antología literaria. Comp. Raquel Chang-Rodríguez y Malva E. Filer. Boston: Heinle, 2013. p. 221-225.

\section{Recebido em 20/07/2015 Aprovado em 31/07/2015}

\footnotetext{
i Luís Ernesto Arévalo. Ph.D., Professor Assistente en Dixie State University, Estados Unidos. Contato: arevalo@dixie.edu

ii En Valparaíso, la Imprenta y Litografía Excélsior publica Azul de Rubén Darío un 30 de julio de 1888.

iii "El velo de la reina Mab" y "A Roosevelt" son dos textos de Darío; el primero enfocado en el efecto envilecedor del liberalismo económico; el segundo, en la proyección del poder militar de los EUA. El primero forma parte de Azul (1888); el segundo, de Cantos de vida y esperanza (1905).
} 